\title{
PROJECT ANQA: \\ DIGITIZING AND DOCUMENTING CULTURAL HERITAGE IN THE MIDDLE EAST
}

\author{
S. Akhtar ${ }^{\text {a }}$, G. Akoglu ${ }^{\text {b }}$, S. Simon ${ }^{\text {c }}$, H. Rushmeier ${ }^{\mathrm{d} *}$ \\ ${ }^{\text {a }}$ Postdoctoral Associate, Dept. of Computer Science, Institute for the Preservation of Cultural Heritage, Yale University - \\ saima.akhtar@yale.edu \\ ${ }^{\mathrm{b}}$ Postdoctoral Associate, Dept. of Computer Science, Institute for the Preservation of Cultural Heritage, Yale University - \\ goze.akoglu@yale.edu \\ ${ }^{c}$ Director of Global Cultural Heritage Initiatives, Institute for the Preservation of Cultural Heritage, Yale University - \\ stefan.simon@yale.edu \\ ${ }^{\mathrm{d}}$ Professor of Computer Science, Yale University - holly.rushmeier@yale.edu
}

Commission II

KEY WORDS: Project Anqa, Cultural Heritage, Digitization, CHER-Ob, Middle East, Syria

\begin{abstract}
:
The practice of digitizing cultural heritage sites is gaining ground among conservation scientists and scholars in architecture, art history, computer science, and related fields. Recently, the location of such sites in areas of intense conflict has highlighted the urgent need for documenting cultural heritage for the purposes of preservation and posterity. The complex histories of such sites requires more than just their digitization, and should also include the meaningful interpretation of buildings and their surroundings with respect to context and intangible values. Project Anqa is an interdisciplinary and multi-partner effort that goes beyond simple digitization to record at-risk heritage sites throughout the Middle East and Saharan Africa, most notably in Syria and Iraq, before they are altered or destroyed. Through a collaborative process, Anqa assembles documentation, historically contextualizes it, and makes data accessible and useful for scholars, peers, and the wider public through state-of-the-art tools. The aim of the project is to engage in capacity-building on the ground in Syria and Iraq, as well as to create an educational web platform that informs viewers about cultural heritage in the region through research, digital storytelling, and the experience of virtual environments.
\end{abstract}

\footnotetext{
* Corresponding author
} 


\section{INTRODUCTION}

\subsection{Background on Project Anqa}

Anqa, taken from the Arabic word for phoenix, is funded by Arcadia Fund - UK, and works through the partnership of CyArk, ICOMOS (International Council on Monuments and Sites), and Yale University. ${ }^{1}$ We work together to deploy international teams and train local professionals in documenting at-risk sites in 3D, conduct scholarly research, and create a web platform to educate the public on the importance of cultural heritage protection and preservation. What sets Anqa apart from other related projects is our effort to build capacity on the ground in the Middle East through in-person and online technical and ethnographic trainings, as well as an emphasis on interpreting data for the dissemination of knowledge, raising awareness around sites located in conflict zones, and storytelling.

\subsection{Partnerships and Goals}

The Project Anqa team at Yale University consists of a number of highly qualified individuals trained in fields ranging from architecture, computer science, art history, Near Eastern studies, conservation, and digital humanities. The interdisciplinary nature of our team closes the gap between the hard and soft sciences so that digital information can be processed, translated, and conveyed to a public in an easily digestible way. Bridging the digital and humanities gap in the practice of cultural heritage documentation also assures greater clarity as data moves from the hands of technologists to domain experts, such as archaeologists or architects, as studies have shown (Alliez, et al., 2017). At the same time, we are designing a section of the web platform to be geared towards deep scholarly inquiries, and we will make RAW and academic data available to researchers at an on-request basis.

The data that we analyze and process for Project Anqa comes through Yale's partnership with CyArk, a Bay-Area based organization that specializes in photogrammetric and laser-light scanning technologies. We work together to train architects, engineers, and computer scientists on the ground, who then collect information that includes RAW and ethnographic data, including field notes, drawings, and sketches of site plans, building structures, and the location of scanners. CyArk works as an intermediary to collect and process RAW data and are an essential member of the project, as they coordinate the on-site technical trainings, communicate regularly and directly with our documentation partners in Damascus, as well as with the team at Yale.

We also emphasize the importance of documentation using what we call the "subjective eye," which is based on a list of intangible categories in accordance with CIDOC-CRM and ICOMOS CIPA standards (Silver, et al., 2016). Photographs, videos, and interviews of building caretakers/users, on-site observations of rituals and processes, and the recording of peculiarities of a building all help in the storytelling process and conveying the importance of cultural heritage preservation for the purposes of posterity.

1 Arcadia Fund - UK, www.arcadiafund.org.uk; CyArk, www.cyark.org; DGAM, http://dgam.gov.sy; Yale Institute for the Preservation of Cultural Heritage (IPCH), http://ipch.yale.edu.
Another important feature of Anqa is that it directly aids in capacity building in areas of high conflict through the coownership of data with on-the-ground teams, who work closely with us to interpret, and socially and historically contextualize these sites. Their experiences, oftentimes living in and among the sites they are helping to document, are an invaluable contribution to the storytelling process, and in turn, are an integral part of documenting intangible aspects of cultural heritage in these areas. Their stories are also the stories of the built environment.

\subsection{Methodology}

The Anqa team works in close collaboration with international scholars and local architects, engineers, and historians to decide on a list of sites that serve a range of social and institutional functions, have historical significance, and are in jeopardy of falling into disrepair or at risk of being damaged. As of the summer of 2017, we are finalizing the documentation of six sites in the old city of Damascus based on discussions with our colleagues at the DGAM, or the Directorate-General of Antiquities and Museums in Syria. In collaboration with CyArk, we have held two 2-week trainings regarding the technical and ethnographic methods of documentation with DGAM team members in Beirut. The DGAM team then went into the field and documented buildings according to the methods we discussed, uploaded the RAW data to the Cloud and a hard disk, and is in the process of sending the data to CyArk. The CyArk team will then process and render the RAW data, and share it on a Cloud storage device with Yale. While data is being collected and processed, the Yale team is building a scholarly database around the six sites, including general historical information about Damascus, Syria, and the broader region, and has designed and coded a digital platform from which information about our chosen sites in Syria and, eventually Iraq, can be disseminated. The remainder of this article will provide a detailed account of the documentation and digitization process for Project Anqa, successes and challenges encountered, and conclusions drawn from our experience thus far. It is our belief that this project has the potential to serve as a foundational platform through which the public can learn about the historic importance of the world's cultural heritage, and the generations of people who have built and continue to inhabit them.

\section{DATA COLLECTION AND FORMS}

\subsection{Capacity Building}

A crucial part of the documentation process for Project Anqa has been to hold technical training seminars in collaboration with CyArk for DGAM team members. So far, two successful trainings have taken place in 2016 and January 2017 in Beirut, and since then, the team has collected a majority of data for the six sites in Syria. The importance of this process lies in our communication with the DGAM team members, most of whom live in and around the sites we are documenting. Our conversations with them give us a window into the lived histories of the sites, and the importance they hold in the vernacular life and language of the city.

We are proud to carry out this project in complete partnership with our DGAM collaborators, who co-own the data they collect and have an equal say in how the data should be presented, contextualized, and disseminated. We strongly feel that this collaborative process, with people who live and work in Syria (and other countries we will work in) is essential -- 
particularly for sites in territories of ongoing conflict. The architects, engineers, and computer scientists with whom we work are hardworking and dedicated to preserving and protecting these sites for the future of their country as much as we are all invested in safeguarding these sites for the purposes of documenting their rich histories. It is through these efforts that trusting relationships can be forged, and the histories and stories of these sites are told through the partnership with people whose heritage these sites are also a part of.

\subsection{Meta-Data Forms and Database}

During the CyArk training, we agreed upon a method of collecting data by using forms that the DGAM team members print out and take with them into the field. We began by working with an existing meta-data form used by the DGAM team on previous projects, and also came up with a list of tangible and intangible categories that work in accordance with CIDOC-CRM and ICOMOS CIPA standards ${ }^{2}$. Figure 1 shows an early iteration of the meta-data form, which includes basic information about the site (site name, year built, architect/patron, location, etc), along with width and dimension of rooms and partitions, description of overall site condition, and a brief history. The additional categories work in tandem with the technical data collected through laser-light scanning and photogrammetry, and falls under a general category called the "subjective eye." This includes general observations of the site, including sketches or notes about unusual markings or inscriptions, contemporary use, interviews with caretakers or visitors, short videos of the sites, or remarks about archival documents or plans that exist in nearby libraries or municipalities.

We have also supplemented the information from the DGAM meta-data forms by building our own multi-lingual literature database at Yale. We are fortunate to have access to a wealth of information in the Yale libraries, along with nearby institutions, from which we collect scholarly citations, articles, photographs, plans, and maps of the sites and surrounding regions. We are confident that the information provided to us through the metadata forms, along with our scholarly research, will provide a fuller view of our six chosen sites alongside the technical data we receive from CyArk.
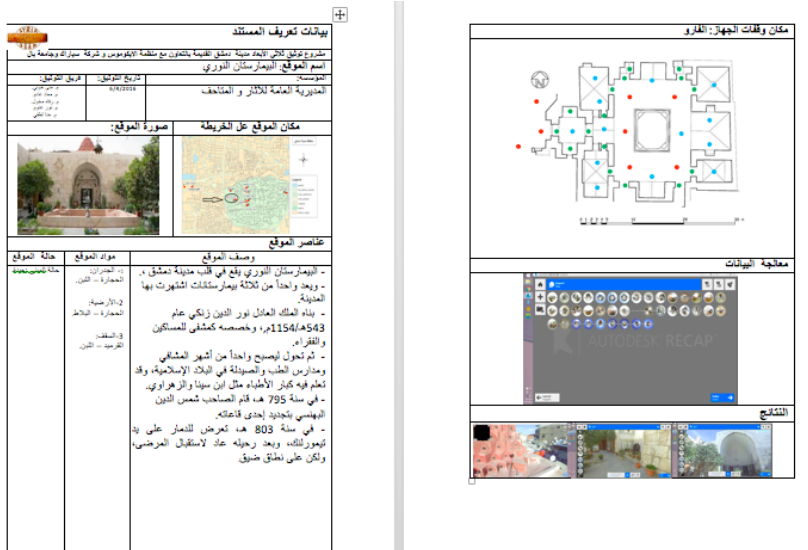

Figure 1. Screen capture of sample DGAM meta-data form

\footnotetext{
2 ICOMOS Charter for the Protection and Management of the Archaeological Heritage (1990),
} http://www.icomos.org/charters/arch_e.pdf.

\subsection{Challenges}

This work has not been without its challenges - any region experiencing an on-going conflict comes with its own set of risks and difficulties, including the safety and well-being of the DGAM team members with whom we are working. In addition to this, we deal with complications in data transfer given the size of the files that are necessary to document entire sites in 3D. Only a segment of this data has been transferred using Cloud services, like Dropbox, and the rest will be transferred onto a hard drive and physically shipped to CyArk, where the data will be downloaded, processed, and rendered. While this is a time-consuming exercise, we are already seeing promising results due to the hard work and dedication of the DGAM team members. Figure 2 shows a screen capture of a high-quality 3D model produced by DGAM of a ceiling in the Al-'Azm Palace. The left side of the image is an untextured mesh, and the right side is textured - these images indicate the extraordinary progress being made by DGAM following the extended training in Beirut, and is a step towards true capacity in the region.

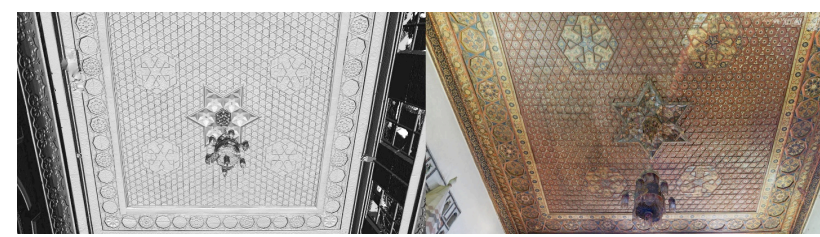

Figure 2: High quality 3D models of Al-'Azm palace ceiling, produced by DGAM

\section{FINAL PRODUCT}

\subsection{Web Platform}

At Yale, we have made significant progress on conceptualizing and preparing a web platform for the dissemination of openaccess data for Project Anqa. We have partnered with and received support from the Yale Digital Humanities Laboratory, which houses and fosters digital humanities projects that focus on communicating stories through a digital platform.

The website is designed to feature three 'themes' through which scholars, professionals and the general public will be able to explore heritage sites: 3D Viewing, Conservation, and Storytelling. The homepage gives a general overview of the Project Anqa mission and locates the six sites on an interactive map (see Figure 3). There will also be a feature that gives an historical and geographic overview of the Middle East region with a special focus on the urban history of Damascus, which situates the sites in relation to one another.

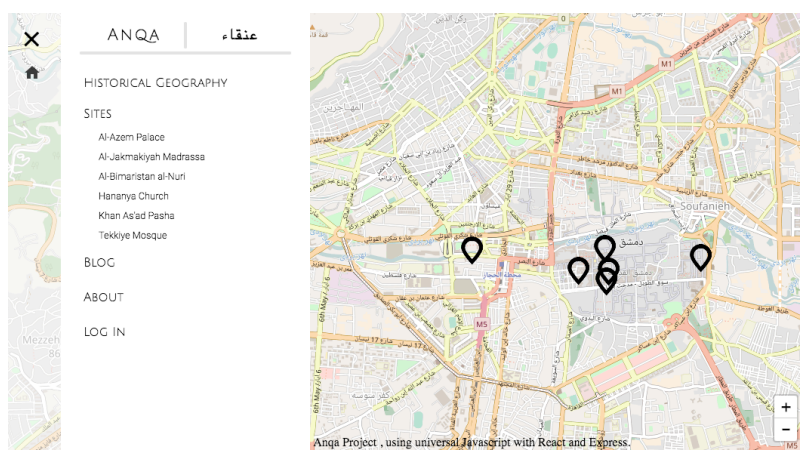

Figure 3. Screen shot of Project Anqa homepage 
The landing page for each site begins with basic information, and proceeds to give an historical overview of the sites construction, use, and architectural layout. Each site can be explored and understood through the three established themes: 3D Viewing allows the exploration of heritage sites through SketchFab and panorama portals which are currently being developed by CS students at Yale University. The Conservation aspect incorporates a state-of-the-art cultural heritage software designed by the Yale Graphics Group called CHER-Ob, which provides annotations that appear on or besides 3D models and/or photographs, and gives information on tangible materials and their values and analysis for conservation professionals. The CHER-Ob program will also feature a video component, which creates short animations of a site or object that highlights material or historical aspects of a site or object and provides annotated explanations. Finally, the Storytelling aspect provides social and historical contexts for heritage sites using the "subjective eye." This includes drawings, photographs, on-site observations of rituals and processes, the recording of peculiarities of a building, and references and citations from existing scholarly publications, which all help in the storytelling process to convey the importance of cultural heritage for the purposes of posterity.

We will also create a portal through which users can register and request RAW data files for deeper scholarly inquiries. The website will initially be published in English, and will eventually be available in Arabic at a later stage. Our intended audience ranges from a general public, to educational institutes (including K-12 schools, colleges, and advanced graduate programs), to scholars who can further their studies based on our data scans and research.

We also intend to incorporate the Arches database, an openaccess platform developed by the Getty Conservation Institute and the World Monuments Fund, which will provide Project Anqa with a base map through which users can locate heritage sites in relation to one another, including those that already exist in the database. The user registration will also allow us to create a "smart" map, where scholars can add information based on their research to a site or object.

\subsection{Incorporating CHER-Ob}

For Project Anqa, we aim to incorporate features from CHER$\mathrm{Ob}$, which is a unified platform developed by the Yale IPCH and Computer Science Graphics Group (Shi, et al, 2014). ${ }^{3}$ The program analyzes and annotates heterogeneous data files about cultural heritage entities, such as 2D images, 3D models, RTI and CT images in addition to their archival/textual data. The main features of the software are the Cultural Heritage Entity (CHE) - which are user defined sets of data, and the Project which are types of studies that are focused on answering specific research questions about a single or plural CHE. Through this platform, users can view, interpret, comment and add new information about a study as it is collected. CHE's are the main source of data to be studied in CHER-Ob. They consist of a set of information uploaded into the software by the user, including image files and annotated data classified according to the Getty Classification of Works of Art, or GCWA (Baca, 2014). All of the images can be annotated, and

\footnotetext{
3 Yale Graphics Group, CHER-Ob, http:/graphics.cs.yale.edu/site/cher-ob-open-source-platformshared-analysis-cultural-heritageresearch?destination $=$ node $\% 2 \mathrm{~F} 196$
}

point, surface, and polygonal annotations are available for 2D, RTI, CT images, including frustum (volumetric) for 3D models. Ultimately, the contribution of this platform is that it facilitates and enables the sharing of a diverse nature of documents for experts from different disciplines.

During the development of a Project, users can explore visualizations and their metadata, add bookmarks, annotations, and new files. They can also search, sort, and filter the data by making use of functions provided in CHER-Ob and generate new knowledge. The progress of the Projects can be tracked by using the navigation tool. The program tracks users' names and timestamps, in addition to evidenced-based statements, which are important features that protect the intellectual rights of each contributor and preserve data provenance information. After the completion of a 'Project', users may also combine new data to the initial $\mathrm{CHE}(\mathrm{s})$, extract sub-projects and merge with other projects. CHER-Ob encourages data sharing and provides customizable automatic report generation option. The content of projects and $\mathrm{CHE}(\mathrm{s})$ can be exported via the report generation function in .pdf and/or video formats, which encourages the distribution of information to non-CHER-Ob users for research, publication and archival purposes. The system offers flexibility, since users can contribute to the wider research scope or to their individual research interests. More importantly, for Anqa, the reports can be used to supplement information on the web platform.

\subsection{Anqa case study: Al-Jakmakiyah Madrasa}

The CHE named 'Al-Jaqmaqiyah Madrasa', for example, includes 2D images and a 3D model of the site provided by DGAM and CyArk. We have supplemented the models with general annotations, surface annotations and volumetric annotations. The general annotations contain historic information, stylistic analysis, and descriptions. The tabs on the right side of the screen provide enhanced access options. Annotations can also be accessed through the 'Navigation' tab, metadata can be viewed and edited through the 'Cultural Heritage Entity' tab, and other functions such as adding general annotations, search, filter, and bookmarks are located at the 'Application' tab (Figure 4).

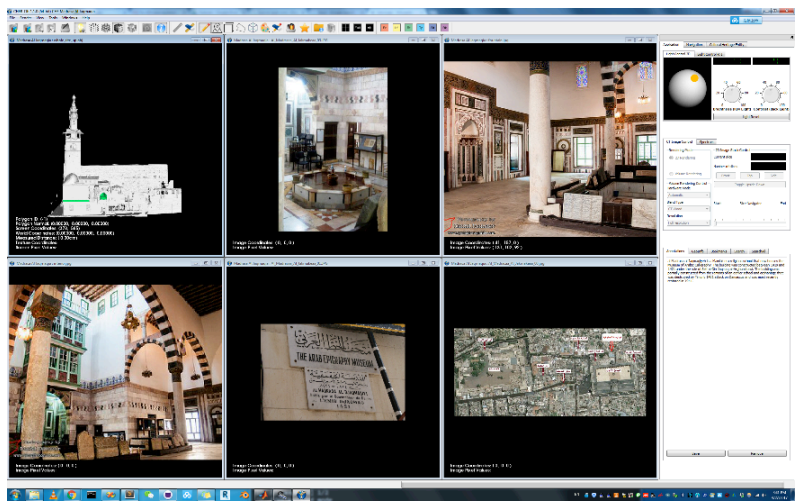

Figure 4. Screenshot from CHER-Ob showing Al-Jakmakiyah Madrasa

The main function of the 'Project' is to link material evidence to intangible aspects such as personal histories, both of which are facing the risk of being lost. The contributions of historians, archaeologists, imaging specialists, conservators and linguists is crucial for the successful execution of a 'Project,' however, public engagement, including members of the local community 
is also indispensable for the documentation of intangible aspects of a cultural heritage site. The report function can also serve as a short introduction to the generation of videos about the sites, which can contribute to the narrative aspect of Project Anqa.

\section{CONCLUSION}

This paper has summarized the main objectives and goals of Project Anqa, which will result in the development of a web platform that will make graphic and textual information available to scholars and the general public. Our argument is that the digital documentation of heritage sites, whether at risk of being destroyed or not, should go beyond simple digitization to include social, historic, and ethnographic information so that these sites can be understood within the contexts in which they are situated. Virtual, or immersive, experiences of the sites are important, as this data gives users an experience of places that they may have limited or restricted access to. However, presenting heritage sites apart from the experiences or stories of local communities and neighborhoods risks disconnecting them from the culture and traditions in which they were created. Our hope is that, through this multi-partnered and interdisciplinary effort, Project Anqa will serve as a foundational platform for the study and documentation of tangible and intangible heritage sites, not only for conflicted regions in the Middle East, but more generally around the world.

\section{ACKNOWLEDGEMENTS}

We would like to thank funders and institutions, without whose support this project would not be possible: The Arcadia Fund UK, The Institute for the Preservation of Cultural Heritage (IPCH) at Yale University, the Department of Computer Science at Yale University, and the Yale University Digital Humanities Lab.

\section{REFERENCES}

Pierre Alliez, Laurent Bergerot, Jean-François Bernard, Clotilde Boust, George Bruseker, et al., 2017. Digital 3D Objects in Art and Humanities: Challenges of Creation, Interoperability and Preservation. White paper: PARTHENOS Workshop held in Bordeaux at Maison des Sciences de l'Homme d'Aquitaine and at Archeovision Lab. (France), November 30th - December 2nd, 2016. A result of the Parthenos workshop. Digital 3D Objects in Art and Humanities: challenges of creation, interoperability and preservation, Nov 2016, Bordeaux, France. pp. 71.

Baca, M., Harpring, P., 2014. CDWA List of Categories and Definitions [WWW Document]. J. Paul Getty Trust. $<$ www.getty.edu/research/publications/electronic_publications/ cdwa/index.html>

Shi, W., E. Kotoula, K. Akoglu, Y. Yang, and H.

Rushmeier, 2014. CHER-Ob: A Tool for Shared Analysis in Cultural Heritage. EUROGRAPHICS Workshop on Graphics and Cultural Heritage, 10/2016. DOI = $\{10.2312 /$ gch. 20161404$\}$

Silver, M., F. Rinaudo, E. Morezzi, F. Quenda, M.L. Moretti, 2016. The CIPA Database for Saving the Heritage of Syria. The International Archives of the Photogrammetry, Remote Sensing and Spatial Information Sciences, Volume XLI-B5, 2016 XXIII ISPRS Congress, 12-19 July 2016, Prague, Czech Republic.

\section{Website References}

Arcadia Fund - UK, //www.arcadiafund.org.uk

CyArk, www.cyark.org

Directorate-General of Antiquities and Museums (DGAM), http://dgam.gov.sy

ICOMOS Charter for the Protection and Management of the Archaeological Heritage (1990), http://www.icomos.org/charters/arch_e.pdf

Yale Graphics Group, CHER-Ob,

http://graphics.cs.yale.edu/site/cher-ob-open-source-platformshared-analysis-cultural-heritageresearch?destination $=$ node $\% 2 \mathrm{~F} 196$ 